\title{
Iniciação Científica na Educação Básica: uma ferramenta essencial para a mobilização mental e construção de conhecimento dos estudantes
}

\author{
Scientific Initiation on Basic Education: an essential tool to \\ students' mental mobilization and knowledge construction
}

Patrícia Fernanda Carmem Kebach ${ }^{1}$

\section{Resumo}

O presente artigo trata de um ensaio teórico sobre o papel da Iniciação Científica, a partir de uma análise piagetiana nos processos de construção de conhecimento. Para isso, a autora realizou uma revisão sobre os conceitos de Piaget voltados para a estruturação mental progressiva, que é uma condição necessária para as aprendizagens. Os termos abstração empírica, reflexionante, pseudo-empírica e refletida, bem como a tomada de consciência são retomados e relacionados às condutas investigativas dos estudantes da Educação Básica, no momento em que buscam compreender e explicar os fenômenos estudados, através de atividades que envolvam pesquisa científica. Neste artigo, propõe-se que a Iniciação Científica é uma potente fonte de construção de conhecimento que gera autonomia, aprendizagem significativa, exercício de argumentação lógica e capacidade de sistematização investigativa precoce dos estudantes.

Palavras-chave: Iniciação Científica. Construção de Conhecimento. Educação Básica.

\begin{abstract}
The following paper presents a theoretical essay on the role of Scientific Initiation, based on a piagetian analysis in processes of knowledge construction. In order to achieve that, the author performed a review of Piaget's concepts aimed at progressive mental structuring, which is a necessary condition for learning. The terms empirical, reflective, pseudo-empirical and reflected abstraction, as well as raising awareness are resumed and related to the investigative behavior of Basic Education students, as they seek to understand and explain the studied phenomena, through activities involving scientific research. In this paper, it is proposed that Scientific Initiation is a powerful source of knowledge construction that generates autonomy, meaningful learning, exercise of logical argumentation and students' capacity for early investigative systematization.
\end{abstract}

Keywords: Scientific Initiation. Knowledge construction. Basic Education.

1 Doutora e mestre em Educação pela Universidade Federal do Rio Grande do Sul (UFRGS), Porto Alegre, RS, Brasil, graduada em Comunicação Social - Publicidade e Propaganda pela Universidade do Vale do Rio dos Sinos (UNISINOS), São Leopoldo, RS. Professora, vice-presidente do Comitê de Pesquisa e coordenadora do Núcleo de Apoio Psicopedagógico (NAP) na Faculdades Integradas de Taquara (FACCAT), Taquara, RS. ORCID: http://orcid.org/0000-0002-3209-9098. E-mail: patriciakebach@faccat.br

Artigo recebido em 13.09.2021 e aceito em 15.10.2021. 


\section{Introdução}

Este artigo tem como objetivo explicar o papel da Iniciação Científica como importante ferramenta para a construção de conhecimento dos estudantes da Educação Básica. Através da epistemologia genética piagetiana, busca-se realizar uma reflexão sobre a importância das atividades de Iniciação Científica, desde a Educação Infantil até o Ensino Médio como fonte de aprendizagem significativa.

A Iniciação Científica, entendida como atividade estratégica para o desenvolvimento científico e tecnológico do País, via de regra, é realizada quase que exclusivamente, a partir do Ensino Superior. Diversas iniciativas, no entanto, vêm ampliando a cobertura dos programas de Iniciação Científica, estimulando que atividades dessa natureza sejam desenvolvidas precocemente, passando por toda a Educação Básica. As pesquisas estão previstas na Base Nacional Comum Curricular (BRASIL, 2017), como se pretende demonstrar, também, no presente ensaio teórico.

A participação em feiras de Iniciação Científica é uma importante fonte de trocas de aprendizagem e ampla construção de conhecimento. É a culminância dos processos de aprendizagem autônoma dos estudantes. Um rico ambiente para exercitar a expressividade e demonstrar todas as práticas e reflexões dos aprendizes, em relação a proposições de soluções para os problemas cotidianos, mapeados nos espaços escolares. É a ultrapassagem de abstrações empíricas rumo a abstrações reflexionantes (PIAGET, 1995), ou seja, não se constatam apenas qualidades inerentes aos objetos observados, mas se vai além, compreendendo-os em sua complexidade progressivamente. Esse processo será explicado no presente ensaio teórico.

Realizar pesquisa nos ambientes de aprendizagem da Educação Básica tem sido uma das ferramentas mais eficazes para a construção de conhecimento dos estudantes, desde a Educação Infantil, já que movimenta coordenação de ações mentais em vários níveis. Recolhem-se dados empíricos, extraindo-se deles conhecimentos, a partir de abstrações pseudo-empíricas, conforme a proposição de Piaget (1995), realizando-se, assim, inferências sobre os eventos, o que provoca implicações significantes, conceitos que se pretende explicar do mesmo modo, a partir do presente artigo. A mobilização mental dos estudantes é, dessa forma, estimulada pelo interesse intrínseco em se aprender mais sobre fenômenos do cotidiano, através de ações significativas, uma vez que partem das eleições temáticas realizadas pelos próprios aprendizes, cujos professores são apenas mediadores dos processos de construção de conhecimento, fornecendo instrumentos para a efetivação da pesquisa.

A pesquisa científica mobiliza a criatividade e a coordenação de ações mentais em vários níveis, dos mais simples aos mais complexos, pois, através dela, o aprendiz poderá estabelecer relações entre variáveis, extraídas do contexto investigado, procurando compreender em profundidade os fenômenos observados. Pretende-se, assim, teoricamente, analisar esse processo no presente ensaio reflexivo.

$\mathrm{O}$ artigo, portanto, pretende realizar uma análise piagetiana sobre a pesquisa, como ferramenta que contribui para a Iniciação Científica e aprendizagem significativa em todos os níveis da Educação Básica e para uma construção de conhecimento rica em significados e autonomia dos estudantes nas diversas áreas de conhecimento, e não apenas na área das Ciências da Natureza (BRASIL, 2017).

\section{0 papel da pesquisa na construção de conhecimento}

A capacidade de análise, síntese, crítica e criação de soluções são os níveis mais complexos de ações mentais propostos por Bloom (1956 apud FERRAZ; BELHOT, 2010) e aparecem claramente nas pesquisas realizadas pelos estudantes, de acordo com os níveis educacionais nos quais se encontram.

O ser humano, valendo-se de suas capacidades, procura conhecer o mundo que o rodeia. Ao longo dos séculos, vem desenvolvendo sistemas mais ou menos elaborados que lhe permitem conhecer a natureza das coisas e o comportamento das pessoas. (GIL, 2016, p. 1).

Dessa forma, a busca pelo conhecimento é o alvo da Educação. E a sistematização de ferramentas pela busca de conhecimentos é o que os transforma em científicos.

A Iniciação Científica é uma ferramenta essencial para a construção de conhecimento, exercício de planejamento, organização mental, através da criação de hipóteses, testagem e prática de escrita argumentativa, o que gera autonomia, protagonismo, criticidade e cidadania. Não se trata de pensar ações de pesquisa apenas nos espaços do componente curricular Ciências ou no Ensino Superior, e sim, como uma forma de aprender sobre quaisquer tipos de objetos de conhecimento já na Educação Básica, desde a Educação Infantil.

A Educação, em todas as suas esferas de atuação, tem discutido amplamente as necessárias modificações no processo de ensino-aprendizagem. Essas modificações se fazem presentes em diferentes 
instâncias do processo educativo, desde a formulação de Políticas pelo Ministério da Educação até o chão da sala de aula. (OVIGLI, 2014, p. 1).

Essas mudanças têm base nos documentos legislativos e promovem a reflexão de se trabalhar de forma contextualizada e interdisciplinar. Para isso, a investigação, no que tange a ações de resoluções de problemas, questionamentos e projetos científicos, com base na possibilitade de se enxergar os objetos de conhecimento por vários ângulos, promove o aprimoramento das habilidades cognitivas e, portanto, $\mathrm{o}$ raciocínio dos estudantes. Buscando solucionar problemas, é preciso realizar revisões teóricas, cálculos, interpretar fenômenos, organizar etapas, o que culminará numa aprendizagem significativa, expressa, por exemplo, nos espaços das feiras de ciências, que necessitam de "providências e atitudes antecipadamente programadas como qualquer outra atividade de ensino-aprendizagem". (OVIGLI, 2014, p. 5).

Assim, pesquisas geram conhecimento. Mas que conhecimento é esse gerado cientificamente? Gil (2016, p. 2), ao refletir sobre ciência, postula o seguinte:

Etimologicamente, ciência significa conhecimento. Não há dúvida, porém, quanto à inadequação desta definição, considerando-se o atual estágio de desenvolvimento da ciência. Há conhecimentos que não pertencem à ciência, como o conhecimento vulgar, o religioso e, em certa acepção, o filosófico.

Portanto, o autor, não satisfeito com tal conceito etimológico, procura defini-la da seguinte forma:

Pode-se considerar ciência como forma de conhecimento que tem por objetivo formular, mediante linguagem rigorosa e apropriada - se possível, com auxílio da linguagem matemática, leis que regem fenômenos (GIL, 2016, p. 2).

Para o autor, essas leis são comprováveis, através de experimentações e observações, características da pesquisa e, muitas vezes, podem proporcionar subsídios para resolver problemas e prever acontecimentos futuros. É, portanto, um conhecimento "objetivo, racional, sistemático, geral, verificável e falível" (GIL, 2016, p. 2) por reconhecer sua própria capacidade de errar. Desse modo, é um conhecimento de natureza lógico-racional que pode ser desenvolvido, à medida que os estudantes, precocemente, sejam incentivados a raciocinarem sobre situações desafiadoras do cotiando, em um contexto cultural particular. Em cada nível da Educação Básica, é necessário, entretanto, que os professores, para conduzirem atividades de pesquisa, estejam cientes dos estágios de desenvolvimento (PIAGET, 1990) dos estudantes, uma vez que as possibilidades de ação dependem das esquemas mentais do sujeito que pesquisa.

Tendo a ciência o objetivo de buscar a veracidade dos fatos, esses são gerados a partir de operações mentais e técnicas que permitem sua verificação. $\mathrm{O}$ percurso para se chegar aos resultados esperados necessita de um método. Assim, o método científico demanda um conjunto de procedimentos intelectuais e técnicos, para que se possa construir novos conhecimentos. Esses procedimentos intelectuais dependem, portanto, das estruturas de conhecimento dos estudantes, em termos de complexidade e, é a partir disso que se elegem os procedimentos técnicos. Dessa forma, pode-se observar as relações entre operações mentais, em seus diferentes níveis, e ações de pesquisa. As pesquisas, portanto, seus procedimentos técnicos, aliados às operações mentais, mobilizam o sujeito e o fazem agir "embarcando numa aventura intelectual" rumo a novas descobertas.

Ao pensarmos a dinâmica do mundo da pesquisa, a grande maioria das pessoas a atrela ao espaço das instituições de Ensino Superior, visto que, por muito tempo esse pensamento era concebível, pela construção histórica que nossas escolas passaram, vista apenas como depósitos de crianças, formadoras de massas de trabalhadores, ou simples mão-de-obra, desatrelando o trabalho físico do intelectual. (PINZAN; LIMA, 2014, p. 2).

Assim, a Iniciação Científica, apesar de ser, na maioria das vezes, relacionada às ações dos adultos, pode ser iniciada cedo, pois, apesar das estruturas mentais de adultos e crianças serem diferentes, conforme Piaget (1995), o funcionamento da cognição humana é sempre o mesmo: parte da ação à compreensão, através de processos de abstrações reflexionantes.

Em relação às crianças da Educação Infantil, por exemplo, os fatos do cotidiano são preciosas oportunidades para se realizar novas descobertas, através de pesquisas simples: uma folha que cai, o rádio quebrado, os fenômenos da natureza, a lagartixa que aparece na sala, o ruído do grilo, etc. Todos os fatos cotidianos são oportunidades para uma aventura intelectual.

A ciência encontra-se, hoje, no centro da atividade educativa do mundo. Por isso mesmo, o desenvolvimento do pensamento científico na Educação Infantil é um desafio (SIMONSTEIN FUENTES, 2011, p. 125).

Para o autor, também nos outros níveis da Educação Básica, não se deve ter como meta ensinar apenas ciências, e sim, "despertar o pensamento independente, a possibilidade de compreender o entorno, 
questionar o mundo e investigá-lo". (SIMONSTEIN FUENTES, 2011, p. 125).

Numa pesquisa científica, ao questionar os estudantes, o professor gera ação mental que demanda reflexão e reflexionamento, para que haja estruturação de pensamento. Num processo que Piaget (1995) chamaria de equilibração majorante, o ser humano desenvolve esquemas mentais para dar conta da realidade que o cerca e que são mobilizados diante de novos desafios do cotidiano, desequilibrando-o mentalmente. Esses elementos conturbadores demandam reorganização mental e esse processo persiste pela vida afora, demandando do ser humano que ele elabore percepções mais rebuscadas sucessiva e infindamente (DEMO, 2010). A atuação do sujeito exige, assim, ações de explorar, observar, comparar, pesquisar, relacionar, discriminar, levantar hipóteses, concluir, posicionar-se, etc. Dessa forma, para se aprender, é necessário que se aja sobre o meio, e a pesquisa pode enriquecer a ação do indivíduo, por envolver essas diversas formas de procedimentos.

O processo de construção de conhecimento está ligado a esse mecanismo de equilibração majorante. O desenvolvimento depende de uma equilibração progressiva, que se caracteriza pela "passagem contínua de um estado de menor equilíbrio a um estado de equilíbrio superior". (PIAGET, 1943 apud MONTANGERO; MAURICE-NAVILLE, 1998, p. 151). Esse processo se dá em torno de um vetor imanente de transformação epistêmica (LAJONQUIĖRE, 1999), ou seja, de construções cognitivas progressivas, prolongando a tendência geral da vida orgânica a uma conquista do meio, isto é, a tendência fundamental à assimilação (PIAGET, 1978a, 1978b). A energia que mobiliza essa tendência está ligada à afetividade. É o desejo (o interesse), portanto, o que mobiliza os sujeitos a construírem o conhecimento. Uma vez que os estudantes estejam engajados, através da curiosidade despertada por alguma situação problema no cotidiano escolar, irão a fundo descobrir mais sobre o tema em jogo, realizando pesquisas e assimilando novos conhecimentos.

Resumidamente, a partir da Epistemologia Genética piagetiana, a estruturação mental cognitiva se dá na interação entre sujeito e objeto. Essa construção é potencializada pelas trocas em ambiente coletivo e em ações que partam do interesse em conhecer, pesquisar, questionar os fatos tematizados. Através de uma postura de pesquisa, exercita-se a argumentação e se buscam as razões científicas e lógico-experimentais.
Mas o que significa pesquisa? Para PerretClermont (1996), ela significa confrontação de pontos de vista diferenciados, resolução de conflitos sócio-cognitivos. Uma vontade de aprender, de elucidar, de descobrir os mecanismos escondidos, as causas, as interdependências entre variáveis de um mesmo objeto investigado. Poderíamos dizer que a pesquisa está ligada à tarefa de abertura criativa a um caminho incerto, é um mistério estimulante ou aventura intelectual.

Para Piaget (1973), a criança se assemelha ao cientista, na medida em que age sobre o mundo físico e social, estruturando seu conhecimento lógico-matemático para dar sentido à realidade. Apesar das diferenças estruturais entre crianças e adultos, é importante que se leve em consideração esta conduta espontânea infantil para se mediar processos de ensino e aprendizagem mais significativos, através da Iniciação Científica.

Para a sistematização de uma pesquisa científica, é necessário a utilização, invenção ou adaptação de métodos de observação e análise. Essa sistematização depende das possibilidades de atuação dos estudantes. Em qualquer nível, a Iniciação Científica está ligada a um método, portanto, de apropriação ativa de conhecimento.

Um ser que se desenvolve e aprende é um "pesquisador", pois procura compreender o mundo e agir sobre ele. Nesse sentido geral, a pesquisa é um seguimento de desequilíbrios e equilibrações, de desorganizações e de reestruturações, de momentos de generalização, de diferenciação, de coordenação dos conhecimentos e de esquemas de pensamento adquiridos. (PERRENOUD, 1991).

Conhecimento meramente reproduzido é plágio. Plágio, portanto, é cópia de conhecimento com domínio de autoria. Muitas vezes, é reproduzido sem qualquer significado. Entretanto, reconstruir para si os objetos tematizados proporciona ao sujeito construções cognitivas capazes de serem generalizadas em diversas situações desafiadoras do cotidiano. Isso Piaget (1977) chama de inteligência: a capacidade de dar conta dos desafios complexos do cotidiano, através da ação que provoca adaptação. Pode-se pensar no conhecimento como uma dinâmica em permanente desconstrução e reconstrução. Alfabetizar cientificamente, para Demo (2010), significa fazer com que o estudante saiba pensar a prática, manipule cenários concretos, pois o conhecimento abstrato é algo que se adquire apenas no estádio de desenvolvimento mais avançado: o operatório formal (PIAGET, 1990). 
Assim, as realidades não classificadas não são manipuláveis, por mais que saibamos que as classificações sejam sempre reducionistas. Entretanto, é assim que o sujeito assimila objetos: por esquemas simplificados para a compreensão dos fenômenos.

As primeiras ações realizadas sobre um objeto novo de conhecimento, costumam estar voltadas para ações simples, ou seja, detém-se apenas nas características materiais dos objetos ou nas próprias ações, num amplo ato de exploração, em que se observam as propriedades físicas em jogo. Assim, no primeiro contato, detemo-nos nos observáveis, em suas características físicas, sem que realizemos comparações ou relações entre os elementos que compõem o objeto de nossa observação. Esse tipo de ação, Piaget (1995) chama de abstração empírica, cuja fonte de ação é exógena e pode levar a êxitos imediatos sobre os objetos, por exemplo, identificar cor, formato, uso prático, mas sem mantê-los, quando deve fazer isso de modo consciente ou na ausência do objeto. Essa ação não garante a generalização do ato, para a resolução de problemas futuros, pois é um processo de construção dos observáveis parcial, baseado em percepções imediatas, sem novas construções. A atuação, a partir de uma aprendizagem superficial por memorização de respostas, por exemplo, não mobiliza ações mentais suficientes para uma compreensão e contextualização de fenômenos. Assim, através desse nível de ação não há real compreensão sobre os fatos, mas apenas constatação de aspectos, sem o conhecimento das implicações significantes que causaram o fenômeno, ou seja, "a relação entre duas significações tal que a primeira conduz à segunda". (PIAGET, 1944 apud MONTANGERO; MAURICE-NAVILLE, 1998, p. 196). Na prática do cotidiano escolar, poderíamos exemplificar esse tipo de abstração por verbos como: nomear, identificar, repetir, memorizar, recordar, reconhecer. Essas ações, geralmente, são demandadas em aulas com concepções teóricas mais tradicionais e, na verdade, podem não gerar efetiva aprendizagem.

É preciso ir além, investigar em profundidade, determinado objeto de conhecimento através de coordenação de ações mentais mais complexas, para que, de fato, se compreenda o que está em jogo nas relações entre causa e efeito.

Mas qual seria o tipo de ação mais complexa, capaz de gerar tomada de consciência e compreensão profunda sobre os fenômenos de investigação? Piaget (1995) utiliza o termo abstração reflexionante, para denominar as ações que geram o processo de construção de conhecimento, em níveis progressivamente mais complexos. As abstrações empíricas, apesar de possuírem sua origem nas abstrações reflexionantes, geram apenas constatações imediatas, sem que haja evolução no pensamento, pois não se diferencia nem se integra novas propriedades do objeto às estruturas de pensamento de quem procura assimilá-lo. Desse modo, o sujeito explora os objetos, sem possuir esquemas suficientes para uma possível inferência lógica. Entretanto, essa exploração é importante, pois constitui a fonte das primeiras pesquisas sobre os temas investigados. Mas, é preciso ir além e realizar ações em patamar superior, para um conhecimento mais profundo. Para explicar um nível de abstração mais complexa, que caracteriza o processo de diferenciação dos elementos, em jogo, em uma determinada estrutura e integração dos mesmos, nas estruturas mentais em forma de novos esquemas de ação, Piaget (1995) utiliza, portanto, o conceito de abstração reflexionante.

Antes de compreender o fenômeno de abstração reflexionante, é importante conceituar o termo diferenciação. Diferenciação (PIAGET, 1995) é o produto da abstração que ocorre, quando o sujeito busca conhecer algo. Conforme o sujeito aprende, a diferenciação é o que o sujeito projeta no objeto para dele extrair conhecimento. Assim, diferenciações são instrumentos de assimilação ou modos de abordar o objeto e não propriamente o conteúdo. Entretanto, o conteúdo se articula com a forma de apreendê-lo, mas não se pode dizer que a distinção entre os elementos de um objeto é diretamente integrada às estruturas mentais, pois essa distinção depende de percepções imediatas e a diferenciação tem a ver com a assimilação e certa generalização que só é possível, através de abstrações reflexionantes.

A abstração reflexionante (PIAGET, 1995) possui fonte endógena e consiste em retirar das coordenações de ações novas características (materiais ou mentais) que o próprio sujeito exerce sobre os objetos, no momento em que procura conhecer algo novo. Através do estabelecimento de relação entre a novidade e aquilo que já conhece, o sujeito amplia suas estruturas cognitivas e poderá usar esse conhecimento em eventos futuros. Diferencia, portanto, determinadas propriedades e integra o novo conhecimento às suas estruturas mentais. Ao observar esse conceito de Piaget, é possível relacioná-lo diretamente à conduta investigativa dos aprendizes, uma vez que precisam coordenar ações mentais, para compreenderem um fenômeno, através de condutas de observação, categorização, classificação, análise comparativa ou crítica e todas as espécies de ações mentais necessárias para 
se inferir e se chegar a conclusões lógicas sobre as explicações de um determinado evento.

Há, portanto, a necessidade de mobilização mental, quando se faz pesquisa, desde a geração de hipóteses, até a elaboração de objetivos e a criação de mecanismos de coleta de dados para se responder aos questionamentos iniciais. É preciso inferir, não somente sobre o material coletado em "fontes de papel" (documentos ou textos), mas também interpretar os dados coletados empiricamente, através de experimentos, entrevistas, observações, etc. Essa interpretação só é possível de ser realizada à luz dos conhecimentos prévios ou, como diz Piaget (1990), de esquemas generalizados. Assim, a construção de conhecimento pela pesquisa proporciona regulações ativas e progressivamente vai permitindo tomadas de consciência. Pode-se, dessa forma, dizer que através de abstrações reflexionantes, o estudante realiza ações mais complexas e, por isso, mobiliza efetivamente seus esquemas mentais, o que gera uma aprendizagem muito mais significativa.

Mesmo com crianças pequenas, é possível mapear hipóteses e, mesmo que de forma mais simples, os professores podem conduzir a Iniciação Científica, fazendo com que as crianças coletem dados e realizem inferências sobre o material coletado, buscando as possíveis respostas aos fenômenos investigados. Esse exercício mental infantil e a aposta do professor no fato de que a criança é capaz de produção de conhecimento muito precocemente é essencial para o desenvolvimento da inteligência e da autonomia.

Segundo Piaget (1974), a ação precede a compreensão, ou seja, o sujeito pode obter êxitos no nível prático, o que não o leva necessariamente a conseguir explicar de que modo agiu para realizar determinada tarefa. A compreensão é uma ação bem mais complexa que requer nova reorganização mental. O processo que leva à compreensão é realizado pela tomada de consciência dos mecanismos em jogo (regulações ativas, coordenação de ações, organizações, encadeamento de ações, etc.) no momento de realização de ações sobre os objetos, visando à resolução de problemas. Portanto, problematizar as cenas do cotidiano escolar, buscando respostas para se concluir algo e se atingir resultados, que podem gerar êxitos ou erros, através de reflexões e pesquisas, contribui muito para as aprendizagens mais profundas sobre os objetos de conhecimento.

No sentido amplo, dessa forma, as abstrações reflexionante envolvem processos de abstrações pseudo-empírica e refletida (PIAGET, 1995).
Especialmente na Iniciação Científica, as abstrações pseudo-empíricas são as mais necessárias, uma vez que os estudantes acionam uma inteligência mais prática do que formal, para que consigam compreender os fenômenos numa investigação científica.

Para que o leitor possa entender esse tipo de abstração, traz-se seu conceito. Abstrações pseudo-empíricas são diferentes das empíricas, à medida que nessas primeiras o que está em jogo não são as características observáveis dos objetos, mas as coordenações de ações projetadas nos objetos e nas ações em suas características materiais. As abstrações pseudo-empíricas são reflexionantes e, portanto, através delas, o sujeito pode comparar, medir, identificar, enfim, estabelecer uma série de relações entre aquilo que observa empiricamente e suas próprias inferências mentais sobre os fenômenos que busca compreender. Diferencia e integra essas novas propriedade, ou seja, os aspectos observados e inferidos e transformados em novos conhecimentos às suas estruturas mentais. E isso é o que gera o conhecimento.

Dito de outro modo, enquanto na abstração empírica se observam elementos isolados da estrutura em jogo, na tentativa de resolução dos problemas, na abstração pseudo-empírica ocorre o estabelecimento de relações em nível mental. Essas relações são feitas entre aquilo que o sujeito observa nos objetos (suas características materiais) ou entre a comparação de um objeto presente e outro ausente, apenas representado mentalmente. Ou seja, o sujeito compara o que havia observado em momentos passados com o que observa, manipula ou experimenta atualmente. Ao realizar abstrações pseudo-empíricas, o sujeito já tem esquemas suficientes ou um esquema básico mental, para que possa coordenar suas ações, através do estabelecimento de relações entre os elementos do objeto que investiga, aprendendo-o e ampliando seus esquemas de ação. A abstração pseudo-empírica é a que mais se aproxima das condutas do nível operatório concreto (PIAGET, 1990), ou seja, operação sobre dados concretos. Existe, nesse nível, tomada de consciência (PIAGET, 1974) ainda parcial sobre as operações realizadas. Desse modo, a inteligência não é ainda formal: não se consegue teorizar com total reversibilidade sobre dados observados e ações realizadas, expressando os eventos, através de implicações significantes, isto é, expressão de significados e a reunião deles, em forma de conexões lógicas. A coleta de dados em experimentos concretos, as observações e registros em Diário de Bordo (ou caderno de campo) são fontes importantes de abstrações 
pseudo-empíricas que podem gerar progressivas tomadas de consciência sobre as relações de causa e efeito de um fenêmeno. Assim, através de ações concretas, assimila-se os objetos tematizados progressivamente.

Desse modo, é possível êxitos na ação dos aprendizes, mas sem que consigam explicar tudo o que realizaram para atingi-los num primeiro momento. Mas é preciso se ter em mente que o exercício da argumentação lógica permite que os estudantes realizem explicações, cada vez mais complexas, com uma progressiva fluência, à medida que, para eles, sejam proporcionados espaços para treinarem suas capacidades argumentativas. Em síntese, pelas abstrações pseudo-empíricas, através de compensações sistemáticas, durante as explicações sobre sua prática, elas podem ser ainda parciais. Mas, esse percurso é necessário, para que haja progressão nas estruturas cognitivas e exercício da capacidade argumentativa.

O quarto tipo de abstração que Piaget (1995) aborda, a abstração refletida, está ligado a um quadro de inteligência superior. Ela consiste em nível superior de reflexão, uma vez que é possível, através dela, estabelecer relações apenas mentais, não havendo a necessidade de ação material do sujeito sobre os objetos para compreendê-los. Nesse caso, em pesquisas mais teóricas, os pesquisadores se utilizam desse tipo de abstração para inferir, a partir de metacognição. Opera-se formalmente. Assim, a abstração reflexionante, em seu sentido restrito, diz respeito às regulações ativas inconscientes (coordenações de ações que caracterizam a inteligência prática). Mas em seus níveis superiores, da abstração refletida, que é acompanhada de tomada de consciência de uma "formalização dos elementos que foram abstraídos". (PIAGET apud MONTANGERO; MAURICE-NAVILLE, 1998, p. 91-92). Essas abstrações iniciam na pré-adolescência, quando se atinge as operações formais. Ao planejar ações de Iniciação Científica que demandem ações mais complexas, é importante que o professor esteja ciente dos estágios de desenvolvimento de sua turma, para que incentive investigações que vão ao encontro das possibilidades de atuação dos estudantes.

Através das informações que o sujeito já retirou e estruturou em ações passadas, ele consegue agir mentalmente, refletindo sobre novas possibilidades de se estruturar o objeto. A abstração refletida é rigorosamente reflexionante, à medida que o sujeito diferencia e integra o novo conhecimento em patamares superiores de sua inteligência. Através desse tipo de abstração, o sujeito consegue expressar, em forma de implicações significantes, suas inferências sobre os dados, condutas criativas e exequíveis e pensar em novas possibilidades de organização dos dados. Nasce daí a capacidade de análise, julgamento, síntese, aplicação e outras ações em nível mais complexo.

A culminância do processo investigativo se dá, desse modo, no estágio operatório formal. Tratase, assim, em níveis superiores de pensamento, das abstrações refletidas (MONTANGERO; MAURICENAVILLE, 1998).

A abstração reflexionante não está necessariamente acompanhada da tomada de consciência, porque não somos sempre conscientes dos novos instrumentos de raciocínio que utilizamos. (MONTANGERO; MAURICE-NAVILLE, 1998, p. 94).

Há tomada de consciência, quando há abstração refletida. O exercício precoce da pesquisa complexifica o pensamento e torna possível sua estruturação progressiva, o que possibilita ao sujeito agir com êxito e pensar sobre sua ação. É o movimento de se debruçar sobre suas próprias ações que torna possível a tomada de consciência (PIAGET, 1974).

Nas metodologias que estão voltadas para a Iniciação Científica, portanto, mobiliza-se as abstrações do sujeito, uma vez que pesquisar é mobilizar o pensamento, uma atividade epistemológica de apreensão do real (SEVERINO, 2016).

\section{A BNCC e o incentivo à Iniciação Científica}

As ideias acima propostas vão ao encontro de algumas competências gerais propostas pela Base Nacional Comum Curricular (BNCC). Nesta parte do artigo, pretende-se analisar de que forma a pesquisa, de forma direta ou indireta, está implícita nesse documento legislativo.

A legislação atual (BRASIL, 2017, p. 9-10) prevê que, em termos de competências gerais, é necessário valorizar e utilizar os conhecimentos historicamente construídos sobre o mundo físico, social, cultural e digital, para entender e explicar a realidade, a fim de continuar aprendendo e colaborar para a construção de uma sociedade justa, democrática e inclusiva. A Base Nacional Comum Curricular também prevê, como competência, o exercício da curiosidade intelectual e recorrer à abordagem própria das ciências, incluindo a investigação, a reflexão, a análise crítica, a imaginação e a criatividade, para investigar causas, elaborar e testar hipóteses, formular e resolver problemas e criar soluções (inclusive tecnológicas) com base nos conhecimentos das diferentes áreas. Desse modo, nesse documento, é possível verificar que há incentivo quanto às ações de Iniciação 
Científica, uma vez que, ao analisarmos esse tipo de ação pedagógica, compreende-se que essa seja um dos principais instrumentos para se exercitar as competências citadas. Além disso, a BNCC prevê que o estudante deve estar apto à utilização de diferentes linguagens, dentre elas: a artística, a matemática e a científica, com a finalidade de se expressar e partilhar informações, experiências, ideias e sentimentos em diferentes contextos (BRASIL, 2017).

Ao se propor atividades de pesquisa, também é possível desenvolver nos estudantes outras competências previstas na BNCC (BRASIL, 2017): compreender, utilizar e criar tecnologias digitais de informação e comunicação de forma crítica, significativa, reflexiva e ética nas diversas práticas sociais (incluindo as escolares) para se comunicar, acessar e disseminar informações; produzir conhecimentos, resolver problemas e exercer protagonismo e autoria na vida pessoal e coletiva; argumentar com base em fatos, dados e informações confiáveis, para formular, negociar e defender ideias, ponto de vista e decisões comuns que respeitem e promovam os direitos humanos, a consciência socioambiental e o consumo responsável em âmbito local, regional e global, com posicionamento ético, em relação ao cuidado de si mesmo, dos outros e do planeta; agir pessoal e coletivamente com autonomia, responsabilidade, flexibilidade, resiliência e determinação, tomando decisões com base em princípios éticos. Todas essas competências podem ser exercitadas, através de uma postura investigativa, reflexiva e crítica, a partir de atividades que envolvam pesquisas científicas. Os temas voltados para as novas tecnologias, para a consciência ecológica, para as atitudes de ética e cidadania, por exemplo, surgem espontaneamente nas problematizações do cotiano escolar. Se os professores incentivarem a atuação curiosa dos estudantes, podem contribuir para que novas pesquisas surjam nesse sentido. É papel dos professores, portanto, proporcionar formas de desenvolver as competências supracitadas e, através das proposições expostas, a Iniciação Científica é uma importante ferramenta para que isso ocorra.

No texto da nova Base (BRASIL, 2017, p. 9), divulgado pelo $\mathrm{MEC}$, especificamente sobre a temática do presente artigo, ao listar as competências gerais, define-se, entre outras, o exercício da curiosidade intelectual, através das ciências. Aborda-se, para isso, "a investigação, a reflexão, a análise crítica, a imaginação e a criatividade, para investigar causas, elaborar e testar hipóteses, formular e resolver problemas e criar soluções". Exercita-se, assim, a curiosidade intelectual dos estudantes, utilizando-se as ciências com criticidade e criatividade, para investigar causas, elaborar e testar hipóteses, formular e resolver problemas e criar soluções.

Basta andar por uma feira científica, para se constatar que as competências previstas na BNCC são desenvolvidas pelos estudantes, quando, com autonomia, argumentação, responsabilidade, reflexão, atitude investigativa e curiosa, procuram resolver problemas e comunicar os resultados de suas pesquisa aos visitantes e avaliadores. Se pensarmos, a partir de uma teoria construtivista e interacionista piagetiana:

O principal objetivo da educação é criar indivíduos capazes de fazer coisas novas e não simplesmente repetir o que as outras gerações fizeram. (PIAGET apud STRECK, 1994, p. 96).

Agir sobre o mundo problematizando-o, através de condutas curiosas, investigativas, críticas e criativas, como o proposto na BNCC, portanto, é ir ao encontro dos preceitos piagetianos.

\section{Aplicação prática da metodologia científica nos espaços de aprendizagem}

Ao realizar pesquisa, a ação mental do estudante é acionada desde a fase da elaboração do projeto científico. Ao observar algum fenômeno do cotidiano, a curiosidade dos aprendizes é despertada e, então, surge a temática a ser investigada. O professor poderá mediar o processo de elaboração do projeto científico, questionando os estudantes sobre o que eles sabem sobre a temática eleita e como eles acham que os fenômenos ocorrem. Das respostas, nascerão as primeiras hipóteses que poderão ser, posteriormente, testadas pela turma de investigadores. Após o mapeamento das primeiras hipóteses, o professor poderá perguntar sobre o que eles gostariam de investigar sobre o fenômeno. Da resposta dos estudantes à questão, portanto, nascerão outros pontos do projeto científico: o problema, as questões norteadoras, o objetivo geral e os objetivos específicos. O último questionamento importante que deve ser feito aos aprendizes é: como podemos investigar este fenômeno? Dito de outro modo, como podemos responder aos questionamentos que estamos fazendo no nosso projeto? A resposta a essa questão traz à tona a metodologia da pesquisa: seu tipo, delineamento, o território de investigação, o universo da amostra, possíveis técnicas de coleta de dados e tipo de análise. Assim, a mediação do professor, ao propor questionamentos aos estudantes, é fundamental para gerar reflexão, para mapear o que já sabem, o que querem saber e como irão investigar a temática eleita. 
A aplicação da metodologia de pesquisa científica em espaços de aprendizagem da Educação Básica implica problematizar o conhecimento, o que suscita a organização e a sistematização do que foi estudado e do que foi aprendido. Estudar é realmente um trabalho difícil. Exige de quem o faz uma postura crítica, sistemática. Exige uma disciplina intelectual que não se ganha, a não ser, praticando-a.

Para Demo (2010), a dinâmica metodológica do conhecimento científico gira em torno da análise prática e teórica da pesquisa como princípio científico e educativo. Portanto, sua definição sobre conhecimento científico reconhece seus limites e imperfeições, uma vez que supõe o ponto de vista de quem define, pois o processo definitório não é coisa irrelevante, haja vista a complexidade dos fenômenos não lineares que não possuem limites estanques e permanecem iguais enquanto mudam.

A criança é um pequeno cientista em potencial. Espontaneamente, age sobre o mundo, testando hipóteses e realizando coordenações de ações mentais. Num primeiro momento, em nível prático e mais simplificado. Entretanto, através do processo de abstração reflexionante (PIAGET, 1995), essas ações vão se complexificando progressivamente.

A pergunta, a problematização e a busca de informações geram interações que tornam os estudantes protagonistas de seus processos de aprendizagem. É possível, dessa forma, incentivar a pesquisa, através de uma postura de alfabetização científica, já nos primeiros anos da Educação Básica, introduzindo-se os estudantes no mundo do conhecimento científico. Os espaços de aprendizagem não precisam se restringir aos muros da escola, embora a escola que realize um trabalho, através de métodos científicos seja um "grande laboratório" para a testagem de hipóteses de seus estudantes. Conforme pensa Demo (2010), a pesquisa é princípio científico e, ao mesmo tempo, educativo. A autoria envolve, portanto, não apenas o orientador da pesquisa, no caso, o professor, mas a todos os estudantes. O princípio filosófico desse tipo de metodologia é a autoridade do argumento e não o argumento da autoridade, conforme pensa o autor. Através da pesquisa, há proposição de conhecimentos inovadores e que fazem, de fato, sentido para os aprendizes, à medida que formulam suas hipóteses e podem testá-las, sem que o conhecimento seja trazido pronto para os espaços de aprendizagem pelo professor.

Quando o aluno aprende a lidar com método, planejar e executar pesquisa, argumentar e contra-argumentar, fundamentar com a autoridade do argumento, não está só "fazendo ciência", está igualmente construindo a cidadania que sabe pensar. (DEMO, 2010, p. 54).

Destarte, a construção da autoria e da autonomia é gerada nas ações de pesquisa. Assim, o processo de investigação, reflexão, análise crítica, imaginação e criatividade, elaboração de hipóteses, formulação e resolução de problemas são as bases da Iniciação Científica, do mesmo modo como compreender, utilizar e criar tecnologias digitais de informação e comunicação de forma crítica, significativa, reflexiva e ética nas diversas práticas sociais poderá ser contemplado com o acesso e utilização das novas tecnologias educacionais, como o previsto na BNCC (BRASIL, 2017).

Ao se proporcionar aos estudantes investigações científicas, ultrapassa-se o instrucionismo e se atua por uma didática da problematização. A habilidade científica do professor é essencial, para que isso aconteça. Toda a escola deve estar preparada para a educação científica e andar na mesma direção, pois ali todos agirão, a partir de condutas autônomas investigativas e criativas. Os materiais didáticos, bem como os laboratórios de diversos tipos, precisam auxiliar no exercício de experimentos científicos, para que haja progressão do pensamento científico dos estudantes que irão preferir a autoridade dos argumentos, sem impor ideias próprias e fixas.

Esse tipo de conduta investigativa desperta a criatividade dos estudantes. Criatividade tem o sentido piagetiano de crescente riqueza de "formas" do pensamento ou criação de novidades produzidas por abstrações reflexionantes que se apoiam sobre todas as atividades cognitivas, no momento de interação entre sujeito e objeto (esquemas de assimilação, coordenação de ações, operações, estruturas, etc.), para delas retirar algumas características e utilizá-las para outras finalidades, ou seja, novas adaptações, novos problemas, etc. (PIAGET, 1995). Essas generalizações são realizadas, portanto, somente através de aprendizagens significativas. Não nascem do ensino conteudista, da repetição mecânica e exaustiva, visando-se apenas à memorização. Nascem, sim, de processos de abstrações reflexionantes, realizadas na dialética entre indução e dedução sobre fenômenos investigados.

\section{Considerações finais}

Este ensaio teórico teve o intuito de realizar uma análise piagetiana sobre a Iniciação Científica, como potente ferramenta de construção de conhecimento, inclusive prevista na BNCC. Procurou-se, aqui, explicar o porquê dessa proposição, com base nas 
explicações sobre a construção de conhecimento e as ações mentais necessárias para isso, através das explicações sobre os tipos de abstrações realizadas pelo sujeito, quando procura compreender determinados fenômenos.

Com base nas proposições piagetianas acima, é possível afirmar que as pesquisas, em forma de Iniciação Científica, desenvolvem habilidades e competências previstas na legislação vigente, contribuem para os processos de ensino e aprendizagem na Educação Básica e para uma construção de conhecimento rica em significados e autonomia dos estudantes. A Iniciação Científica, assim, além de viabilizar a produção de conhecimentos novos, desenvolve a curiosidade, o interesse e o sabor pelo saber, disponibiliza espaços para aventuras intelectuais, exercita a capacidade de argumentação lógica e investigação sistemática sobre os mais variados tipos de objetos do conhecimento. Ela pode ter início na Educação Infantil e perpassar toda a vida acadêmica na Educação Básica. Uma vez que a pesquisa faça parte das atividades do cotiano escolar, é possível exercitar a autonomia, a curiosidade, a criticidade, a argumentação lógica e a criatividade dos estudantes.

Como condições objetivas, para que isso ocorra, além da formação de professores para se desenvolver ações de Iniciação Científica, é preciso proporcionar espaços de aprendizagem com laboratórios, apoio estudantil (inclusive psicológico), enfim, estruturas adequadas, para que se possam realizar as pesquisas na Educação Básica. Uma boa política de formação de professores que garanta uma carreira docente condizente com o papel do professor na sociedade, assim como a efetiva implementação das diretrizes da BNCC, poderão contribuir para a qualificação das atividades de Iniciação Científica em toda a Educação Básica.

\section{Referências}

BRASIL. Ministério da Educação Base Nacional Comum Curricular. 2017. Disponível em: http:// portal.mec.gov.br/index.php?option $=\mathrm{com}_{-}$ docman \&view $=$ download\&alias $=79601$-anexo-textobncc-reexportado-pdf-2\&category_slug=dezembro2017-pdf\&Itemid=30192. Acesso em: 11 mar. 2019.

DEMO, P. Educação e alfabetização científica. São Paulo: Papirus, 2010.

FERRAZ, A. P. C. M.; BELHOT, R. V. Taxonomia de Bloom: revisão teórica e apresentação das adequações do instrumento para definição de objetivos instrucionais. Revista Gestão e Producão, v. 17 , n. 2 , p. $421-431,2010$. DOI: 10.1590/S0104$530 X 2010000200015$.

GIL, A. C. Métodos e técnicas de pesquisa social. 6. ed. São Paulo: Atlas, 2016.

LAJONQUiÈRE, L. De Piaget a Freud: para repensar as aprendizagen: a (psico)pedagogia entre o conhecimento e o saber. Petrópolis: Vozes, 1999.

MONTANGERO, J.; MAURICE-NAVILLE, D. Piaget ou a inteligência em evolução. Porto Alegre: Artmed, 1998.

OVIGLI, D. F. B. Iniciação Científica na educação básica: uma atividade mais do que cecessária. Revista Brasileira de Iniciação Científica, v. 1, n. 1, 2014. Disponível em: https://periodicos.itp.ifsp.edu.br/index. php/IC/article/view/13/425. Acesso em: 13 abr. 2021.

PERRENOUD, P. La maîtrise pratique de la langue, enjeu majeur de la rénovation: entre utopie politique et utopie didactique. Genève : Faculté de Psychologie et des Sciences de l'Éducation, 1991.

PERRET-CLERMONT, A.-N. La construction de l'intelligence dans l'interaction sociale. Neuchâtel, Suisse: Peter Lang, 1996.

PIAGET, J. Abstração reflexionante: relações lógicoaritméticas e ordem das relações espaciais. Porto Alegre: Artes Médicas, 1995.

PIAGET, J. A Epistemologia genética: sabedoria e ilusões da filosofia: problemas de psicologia genética. In: PIAGET. São Paulo: Abril Cultural, 1978a. 426 p. (Coleção Os Pensadores).

PIAGET, J. A formação do símbolo: imitação, jogo e sonho, imagem e representação. Rio de Janeiro: Zahar, 1978b.

PIAGET, J. A linguagem e o pensamento da criança. Rio de Janeiro: Fundo de Cultura, 1973.

PIAGET, J. Epistemologia genética. São Paulo: Martins Fontes, 1990.

PIAGET, J. La prise de conscience. Paris: Presses Universitaires de France, 1974.

PIAGET, J. O desenvolvimento do pensamento: equilibração das estruturas cognitivas. Lisboa: Dom Quixote, 1977.

PINZAN, M. E.; LIMA, A. P. Iniciação Científica na educação básica: uma possibilidade de democratização 
da produção científica. In: ENCONTRO DE SIMONSTEIN FUENTES, S. A educação científica PRODUÇÃO CIENTÍFICA E TECNOLÓGICA, 9., na educação infantil. In: PEREIRA, A. C. (org.). O 2014, Campo Mourão. Anais [...]. Campo Mourão: educador no cotidiano das crianças: organizador e UNESPAR: NUPEM, 2014. Disponível em: http:// problematizador. Brasília: Gerdau: Fundação Maurício www.fecilcam.br/nupem/anais_ix_epct/PDF/ Sirotsky Sobrinho, 2011. Disponível em: https:// TRABALHOS-COMPLETO/Anais-CH/10.pdf. unesdoc.unesco.org/ark:/48223/pf0000214769. Acesso em: 12 abr. 2021. Acesso em: 13 abr. 2021.

SEVERINO, A. J. Metodologia do trabalho científico. STRECK, D. R. Correntes pedagógicas: aproximações São Paulo: Cortez, 2016. com a teologia. São Paulo: Vozes, 1994. 
